\title{
Environmental factor analysis of cholera in China using remote sensing and geographical information systems
}

\author{
M. XU ${ }^{1}$, C. X. $\mathrm{CAO}^{1 *}$, D. C. $\mathrm{WANG}^{2}$, B. KAN ${ }^{2}, Y . F \cdot \mathrm{XU}^{1}, \mathrm{X} . \mathrm{L}^{\mathrm{N}} \mathrm{NI}^{1}$ AND \\ Z. C. $\mathrm{ZHU}^{1}$ \\ ${ }^{1}$ State Key Laboratory of Remote Sensing Science, Institute of Remote Sensing and Digital Earth, Chinese \\ Academy of Sciences, Beijing, China \\ ${ }^{2}$ State Key Laboratory for Infectious Disease Prevention and Control, Institute for Infectious Disease Control and \\ Prevention, Chinese Center for Disease Control and Prevention, Beijing, China
}

Received 14 January 2014; Final revision 10 June 2015; Accepted 2 September 2015; first published online 14 October 2015

\section{SUMMARY}

Cholera is one of a number of infectious diseases that appears to be influenced by climate, geography and other natural environments. This study analysed the environmental factors of the spatial distribution of cholera in China. It shows that temperature, precipitation, elevation, and distance to the coastline have significant impact on the distribution of cholera. It also reveals the oceanic environmental factors associated with cholera in Zhejiang, which is a coastal province of China, using both remote sensing (RS) and geographical information systems (GIS). The analysis has validated the correlation between indirect satellite measurements of sea surface temperature (SST), sea surface height (SSH) and ocean chlorophyll concentration (OCC) and the local number of cholera cases based on 8-year monthly data from 2001 to 2008. The results show the number of cholera cases has been strongly affected by the variables of SST, SSH and OCC.

Utilizing this information, a cholera prediction model has been established based on the oceanic and climatic environmental factors. The model indicates that RS and GIS have great potential for designing an early warning system for cholera.

Key words: Cholera, environmental factors, GIS, remote sensing, spatial analysis.

\section{INTRODUCTION}

Epidemic Vibrio cholerae has two major serogroups (O1 and $\mathrm{O} 139$ ); the $\mathrm{O} 1$ serogroup has two biotypes (classical and El Tor), and each biotype has two major serotypes (Ogawa and Inaba). It is affected by many environmental factors such as temperature, precipitation, elevation, etc., and is spread through contaminated water. Since its first occurrence in the Ganges Delta in India in

\footnotetext{
* Author for correspondence: Dr C. X. Cao, State Key Laboratory of Remote Sensing Science, Institute of Remote Sensing and Digital Earth, Chinese Academy of Sciences, Beijing 100101, China. (Email: caocx@radi.ac.cn)
}

1817, there have been seven major global cholera pandemics causing tremendous disaster to humans, especially in Southern Asian countries such as Bangladesh [1-6] and India [7], and Latin American countries such as Mexico [8] and Peru [9], as well as some African countries [10-15].

China has been involved in all seven of the global cholera pandemics, where the annual cases reported exceeded hundreds of thousands in some years, and the fatality ratio once reached 30\% [16]. Although China's sanitation has improved greatly during recent years with the growth of social and the economic developments, and the incidence of cholera has been controlled to a relatively low level, there are still 
cases of cholera reported nearly every year, especially in the coastal regions. Therefore, study of the environment of cholera in China has significant relevance for the control of cholera in developing countries.

Cholera is one of a number of infectious diseases that appears to be influenced by climate, geography and other natural environmental features such as oceanic factors. Climatic changes are believed to be the most important factors which affect the life-cycle of $V$. cholerae in the natural environment. $V$. cholerae is a component of coastal and estuarine microbial ecosystems, with the copepod species of zooplankton that comprise the aquatic fauna of rivers, bays, estuaries and the open ocean serving as host for the bacterium [17]. Many studies have revealed a markedly strong association between cholera and some regional environmental factors such as the sea and climate [18-20]. One of the main reasons that allow $V$. cholerae to survive and reproduce in the marine and estuarine environment is that the salinity level is appropriate, and there are large numbers of phytoplankton and zooplankton which provide rich vehicles for the spread of $V$. cholerae. The tide drives the seawater containing $V$. cholerae to into estuary waters and it is then spread along the inland rivers. Therefore, to monitor the marine and estuarine environment would support the forecast and early warning of cholera in coastal regions.

Remote sensing (RS) can provide objective geographical, climate and environmental data of the sea, land and atmosphere. It has the advantage of wide coverage, continuous repeated observations and is free from geographical constraints, and could support the study of human epidemics, including cholera, by providing adequate spatial imaging [16, 21, 22]. Geographical information systems (GIS) have been widely employed to directly visualize the dynamics of the transmission of infectious diseases and to identify the spatial distribution and risk factors of the epidemics' outbreak [2, 12, 23-26].

This study aims to reveal the influences of natural environmental factors such as geography and climate on the cholera epidemic in China based on RS and GIS techniques. Due to the characteristics of cholera in coastal area, the association between monthly cholera cases in coastal regions and the sea surface temperature (SST), sea surface height (SSH) and ocean chlorophyll concentration (OCC) for the nearest coastal environment derived from satellite RS data is validated in the study, and the lag effects of these three oceanic environmental factors on the local cholera magnitude is analysed.

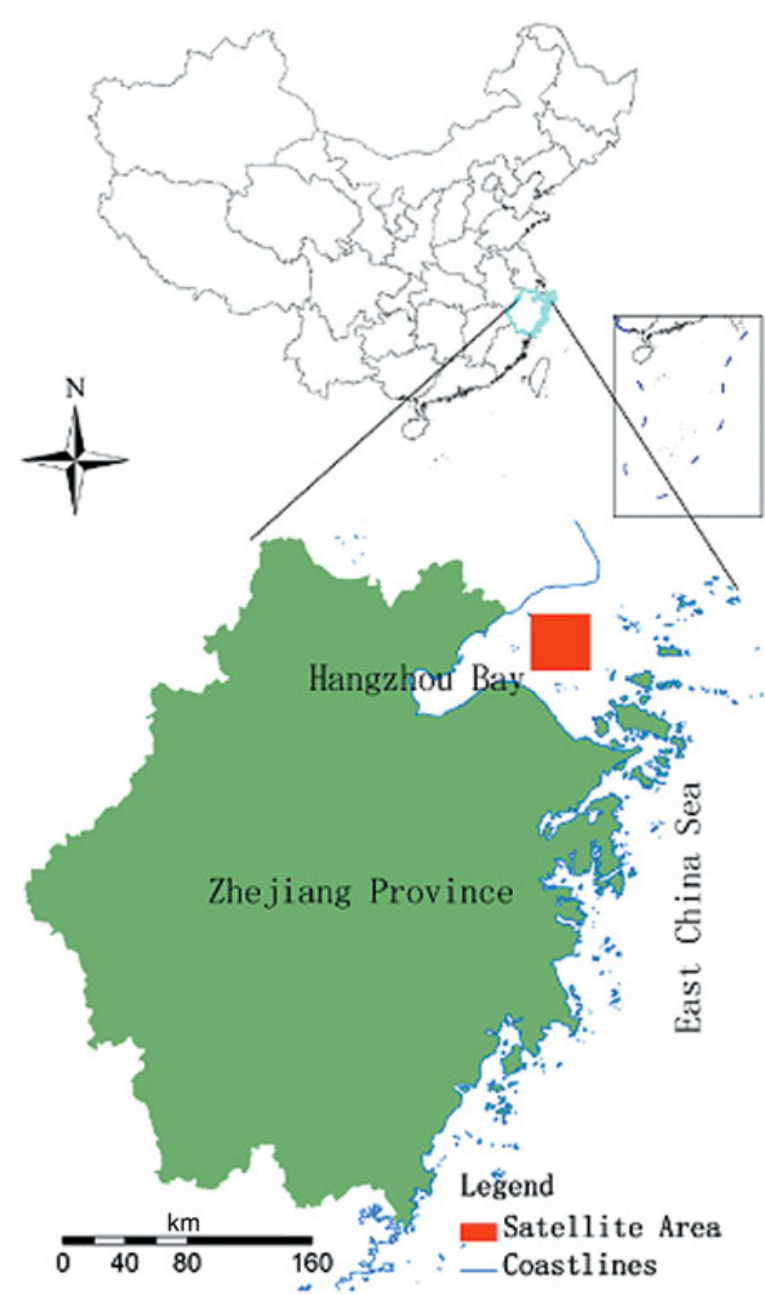

Fig. 1. The upper image indicates the location of Zhejiang province in China, the blue line is the boundary of Zhejiang which is in the southeast of China near the East China Sea. The bottom image is a zoomed in map of Zhejiang province, the red square (centred in $30 \cdot 5^{\circ} \mathrm{N} / 121 \cdot 6^{\circ} \mathrm{E}$ ) is the satellite data area, near Hangzhou Bay in Zhejiang province.

\section{METHODS}

\section{Study area and materials}

We have two spatial scales regarding the study area. One is the whole of China, and the other is a coastal province of China called Zhejiang, which is situated along the shore of the East China Sea (Fig. 1). Zhejiang lies in between north latitude $27^{\circ} 01^{\prime}$ and $31^{\circ} 10^{\prime}$ and east longitude $118^{\circ} 01^{\prime}$ and $123^{\circ} 08^{\prime}$, with a total area of $101800 \mathrm{~km}^{2}$ and a population of $46 \cdot 1$ million. It features complex landforms, with $70 \cdot 4 \%$ of the area comprising of mountainous regions and hills, $23 \cdot 2 \%$ plain and basins, and $6 \cdot 4 \%$ rivers and lakes. Under typical subtropical monsoon conditions, the climate of Zhejiang is characterized by four 
distinctive seasons, abundant sunshine and rainfall, moist air and diverse climate characteristics, with an annual average temperature of $15-18^{\circ} \mathrm{C}$. With 9893 $\mathrm{km}$ of inland waterways, Zhejiang has 5495 inland harbour berths and 958 seaport berths, of which 71 can berth $\geqslant 10000$ tons. Zhejiang is one of the most cholera-prevalent provinces in China. As a coastal region, it has a developed aquaculture and the local inhabitants like to eat seafood. In recent years, there have been cholera outbreaks caused by the consumption of seafood contaminated by $V$. cholerae.

The epidemiological data were collected from the Chinese Center for Disease Control and Prevention (China CDC). The number of cholera cases are recorded by local hospitals or disease control and prevention branches and report to China CDC, which is the basis on which the monthly cholera case magnitude for each county in the study area for 2001 to 2008 is calculated. The fields for each record include county name, county code and cholera case magnitude for each month during 2001 to 2008 .

Basic geographical data is collected from the 1:1000000 national basic scale electronic maps, which are provided by the National Geomatics Center of China. This dataset includes the administrative margin vector of each county, and the national rivers distribution vector. We established a connection between the administrative boundary vector and the cholera and demographic data by using the field 'district code', and generated a new vector which contained the number of cholera cases and population in each county, thereby realizing the spatialization of the cholera and demographic data. We unified the coordinate system through the projection conversion for each layer, and then established the temporal and spatial database of cholera in China.

The digital elevation map (DEM) data were acquired from SRTM (Shuttle Radar Topography Mission) with a spatial resolution of $90 \mathrm{~m}$. The DEM data of SRTM divided the global scale into raster maps with $1^{\circ}$ in the length and width according to the latitude and longitude. We collected the DEM raster maps of SRTM which covered the whole of China. We spliced these images using ENVI 4.5 software (http://en.softonic.com/s/envi-4.5), and then cut the mosaic data based on the administrative boundary vector layer of China. By this method, we obtained the elevation raster layer maps of China.

River density was calculated based on the national rivers distribution vector in the 1:1000000 national basic scale geographical datasets.
The distance from each county to the coastline was calculated using the coastline map of China as the input layer. By computing the distance of the central point of each county to the coastline based on spatial analysis, we generated the corresponding raster layer of the distance to the coastline.

The RS dataset includes SST, SSH and OCC, all of which are satellite-derived RS products. The satellite data for SST were acquired from the National Oceanographic and Atmospheric Administration (NOAA) Advanced Very High Resolution Radiometer (AVHRR). Sea-level anomalies (SLA) acquired from Topex/Poseidon (from 1992 to 2002) or Jason-1 (2002 to present) satellites were used to measure SSH in the study. OCC was acquired from the US satellite SeaStar by sea-viewing wide field-of-view (SeaWiFS), a sensor that is used specifically for measuring chlorophyll a concentration at a spatial resolution of $9 \mathrm{~km}$. Monthly case data were acquired from 2000 to 2008 , monthly environmental variables for SST, SSH and OCC during the same period were extracted for approximately the same region.

\section{Spatial analysis and statistics}

In order to observe the correlations between cholera and the environmental risk factors, the vector layer of the number of cholera cases distributed was respectively overlapped with the vector layers of environmental risk factor in ArcGIS software (version 9.3, ESRI Inc., USA). The layer of temperature, precipitation, relative humidity, sunshine duration, air pressure, elevation, river density and distance to coastline were respectively calculated using spatial analysis. Each environmental risk factor was divided into several levels. Next, the geographical statistic method was employed to extract the number of cholera cases for different levels. The study area of China here only concerns mainland China, and does not include Taiwan, because we did not obtain the data on environmental factors in Taiwan.

\section{Temporal analysis and prediction}

Outbreaks of cholera in coastal areas have different impact factors than in inland areas because they are not only impacted by climatic and geographical factors but also by oceanic factors. To explore the oceanic environmental factors of cholera in Zhejiang, the monthly number of cholera cases from 2001 to 2008 was first summed, based on the monthly statistics of 
cholera cases for all counties. Then, concurrent environmental variables from the global products of SST, SSH and OCC were extracted using three batch programs of IDL 7.0 (docs.astro.columbia.edu/files/ idl/7.0/) which were individually compiled especially for the satellite-derived region in the study. The extracted values of the environmental variables were linked to the monthly records of cholera case magnitude. To analyse the relationship between cholera and the environment, we respectively compared the monthly temporal variation of SST, SSH and OCC with the number of cholera cases. For the environmental factors there was a delayed effect on the recording of cholera outbreaks, so 1-month lag effects for each oceanic environmental variable were created in the study.

The oceanic parameters based on RS data have great potential in developing a cholera prediction model which may provide early warning of cholera outbreaks. Many efforts have been tested to establish the cholera prediction models based on these environmental indicators including temperature, precipitation, SST, SSH and OCC [5, 16, 18]. For new cholera cases, including primary cases which are the result of infection by natural surface water sources, and secondary cases consisting of people that are infected via fecal-oral transmission from infected individuals to susceptible individuals, a generalized linear model (GLM) with a Poisson distribution and a log link was used to established our prediction model, based on the environmental conditions and infected individuals which is written as

$$
\begin{aligned}
\log \left(C h o_{t}\right)= & a_{0}+\sum_{i=1}^{n} b_{i} * \log \left(C h o_{t-i}+1\right) \\
& +\sum_{i=0}^{n} c_{i} * \text { Env }_{t-i}
\end{aligned}
$$

where $C h o_{t}$ represents the number of new cholera cases in month $t$, while $C h o_{t-i}$ represents the number of cholera cases in month $i$ before month $t$, the use of $C h o_{t-i}+1$ in the model is to avoid the non-positive variable in the function of $\log ; a_{0}, b_{i}$ and $c_{i}$ are model parameters, $E n v_{t-i}$ represents environmental conditions which are simply environmental indicators of month $i$, delayed to month $t$ in our study.

\section{RESULTS AND DISCUSSION}

\section{Spatial distribution of cholera in China}

The overlapped map of temperature and cholera cases in China is shown in Figure 2a. According to the spatial statistic (as shown in Table 1), there are no cholera cases distributed in the regions where the annual average temperature is $<5^{\circ} \mathrm{C}$. However, cholera incidence is 1.93 per million in the regions where the annual average temperature is $>20^{\circ} \mathrm{C}$.

The overlapped map of precipitation and cholera cases is shown in Figure $2 b$. The number and percentage of cholera cases for different levels of precipitation are given in Table 2. Cholera incidence rises as the annual average precipitation increases, and $>90 \%$ of cases are located in the humid areas with an annual precipitation of $>800 \mathrm{~mm}$.

As an important geographical environmental element, elevation may significantly impact the distribution of a variety of diseases. The overlapped map of elevation and cholera cases is shown in Figure 2c. The number and percentage of cholera cases for different levels of elevation are given in Table 3. Elevation has a significant impact on the distribution of cholera. Areas of low elevation tend to have more cholera cases. More than $80 \%$ of cholera cases were distributed in the areas with an elevation of $<500 \mathrm{~m}$, while no cases were distributed in areas with $>3000 \mathrm{~m}$ elevation. The reason for this is that $V$. cholerae are mainly spread via water and the areas of low elevation are vulnerable to flooding. Thus, local residents have a higher probability of contact with water or food contaminated by bacterium.

River density reflects the precipitation and the underlying surface condition to a certain extent, which exerts great influence on the risk of cholera outbreaks. The regions of high rainfall and poor permeability have a high risk of flooding which is associated with the outbreak of cholera. Therefore, river density may be an indicator that indirectly reflects the risk of cholera outbreaks. Many studies have revealed that cholera has a strong correlation with the features of local rivers $[27,28]$ which are presumed to be the main approach for the transmission of $V$. cholerae. The overlapped maps of river density and cholera cases are shown in Figure $2 d$. The number and percentage of cholera cases for different levels of river density are given in Table 4. There are cholera cases in all the regions for six different levels of river density, in which the $0 \cdot 02-0 \cdot 04 / \mathrm{km}$ group has the most cholera cases.

Cholera is mainly caused by people directly consuming seafood contaminated by $V$. cholerae over recent years, which is different to the causes of poor quality water and sanitation of decades ago. The closer to the sea, the more abundant seafood becomes, giving the local inhabitants more opportunities to consume 
(a)
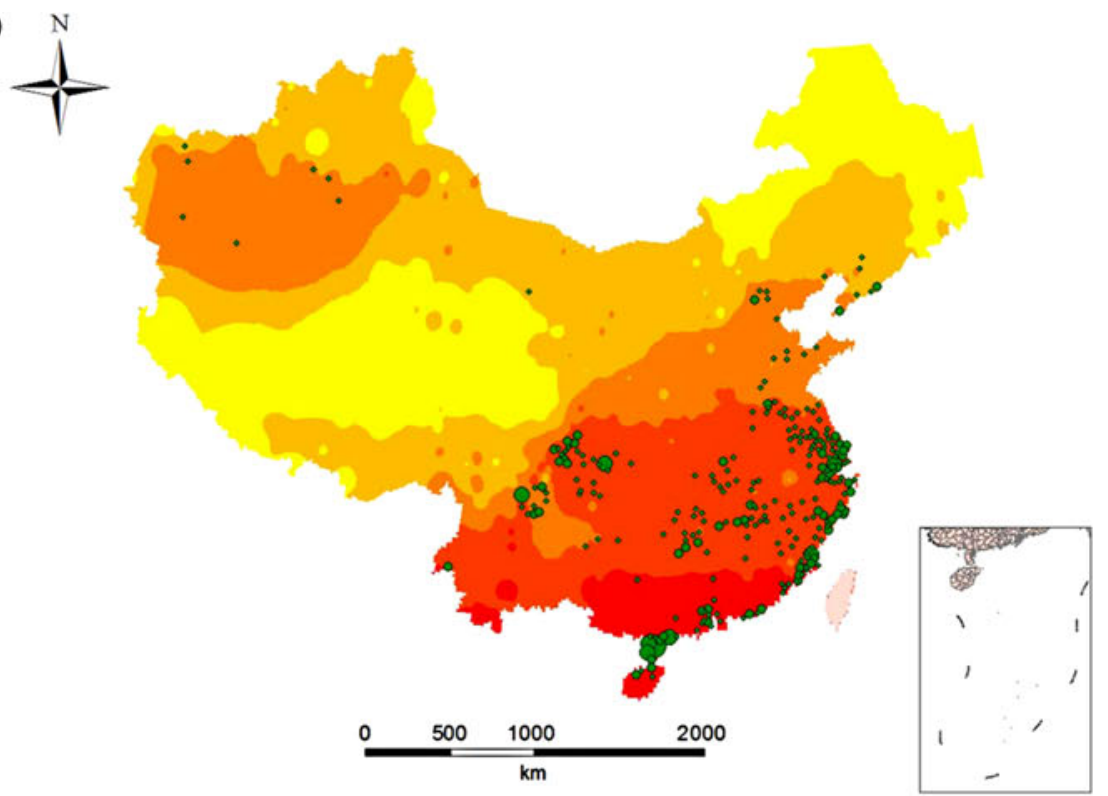

Legend

Cholera Temperature( $\left.{ }^{\circ} \mathrm{C}\right)$

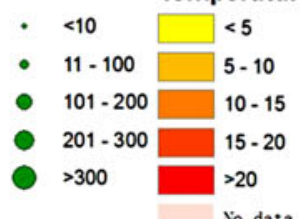

(b)
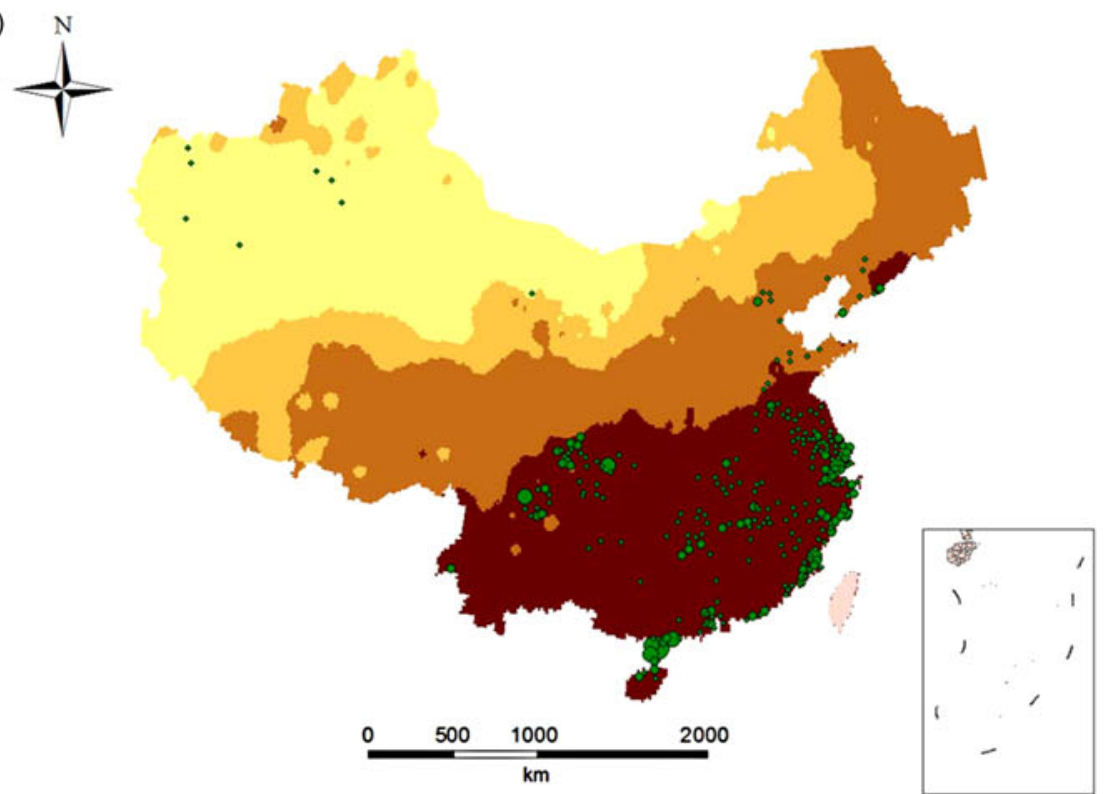

Legend

\begin{tabular}{|c|c|c|}
\hline \multicolumn{2}{|c|}{ Cholera } & Precipitation $(\mathrm{mm})$ \\
\hline . & $<10$ & $\square<200$ \\
\hline & $11-100$ & $200-400$ \\
\hline • & $101-200$ & $400-800$ \\
\hline ○ & $201-300$ & $>800$ \\
\hline O & $>300$ & io data \\
\hline
\end{tabular}

Fig. $2(\boldsymbol{a}, \boldsymbol{b})$. The spatial distribution of cholera cases for different levels for $(a)$ annual average temperature, $(b)$ annual average precipitation. 
(c)

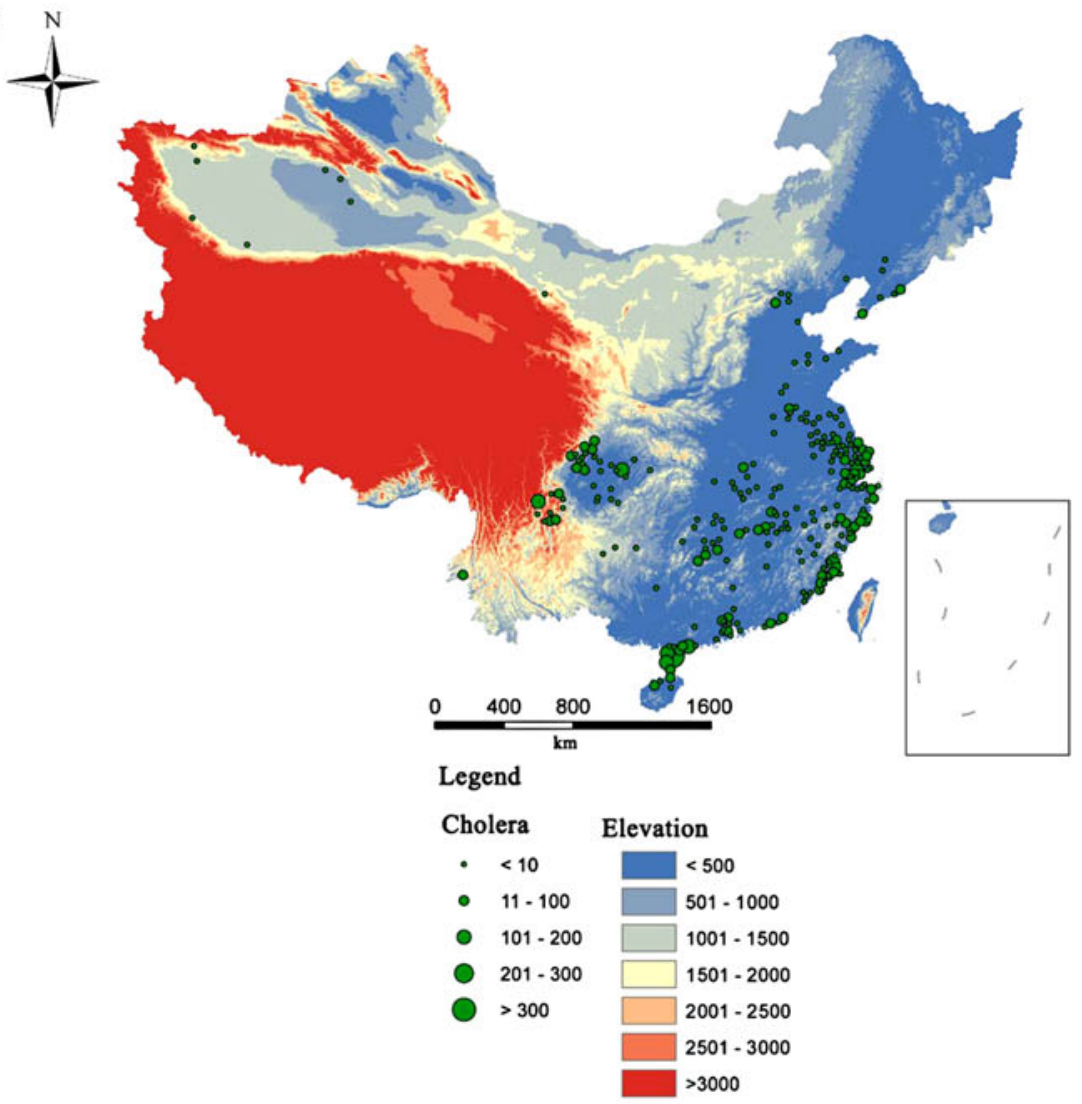

(d)
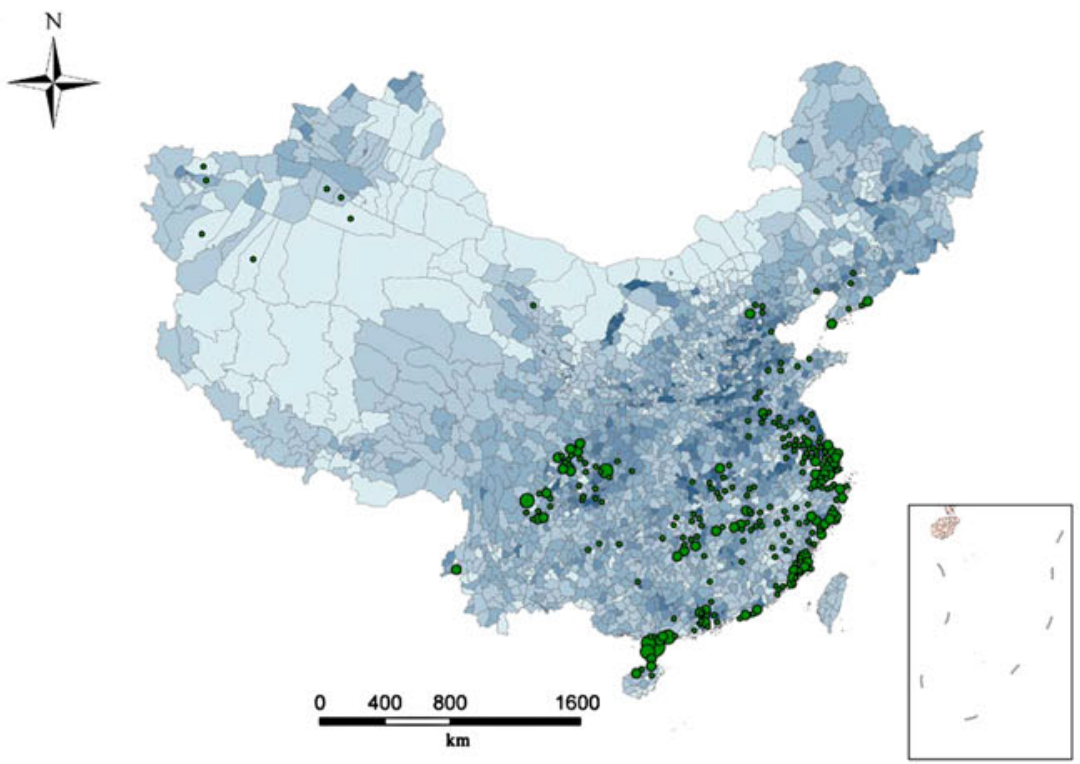

Legend

Cholera River density

- $<10 \quad \square<0.02$

- $11.100 \quad 0.02 \cdot 0.04$

- $101-200 \quad 0.04 \cdot 0.06$

- $201-300 \quad 0.06 \cdot 0.08$

$>300 \quad 0.08-0.10$

$>0.10$

Fig. $2(\boldsymbol{c}, \boldsymbol{d})$. The spatial distribution of cholera cases for different levels for $(c)$ elevation, $(d)$ river density. 
(e)<smiles>CC(C)NC(C)C</smiles>

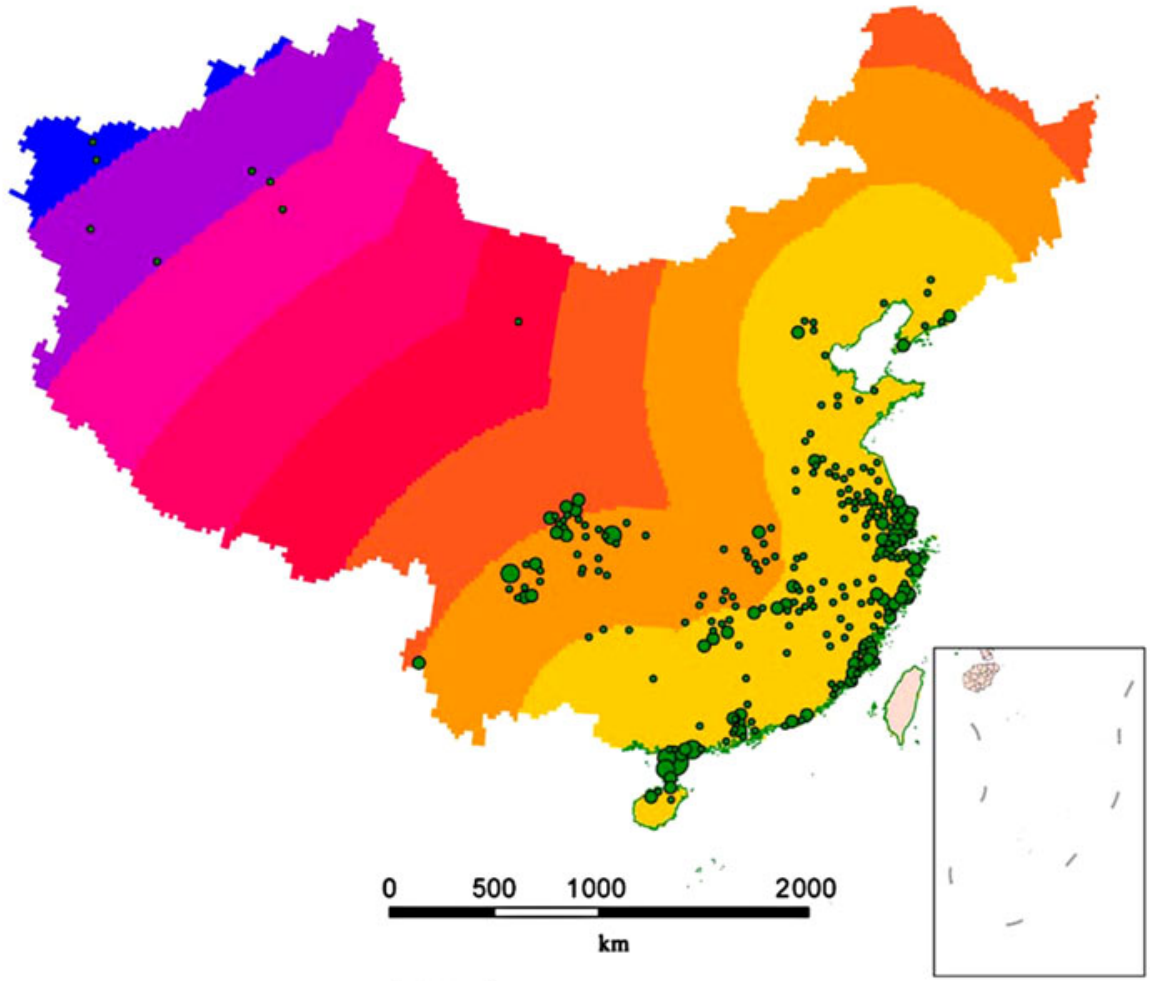

Legend

Cholera Distance to coastline

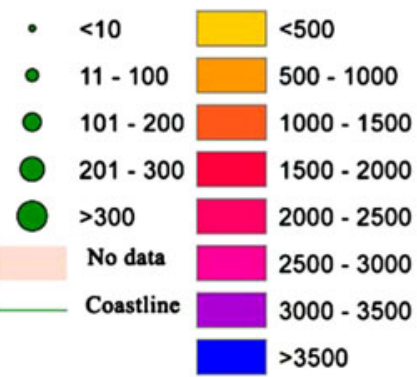

Fig. 2e. The spatial distribution of cholera cases for different levels for distance to the coastline.

Table 1. Statistical analysis of temperature and cholera in China between 2001 and 2008

\begin{tabular}{lclcc}
\hline \hline $\begin{array}{l}\text { Average } \\
\text { temperature }\left({ }^{\circ} \mathrm{C}\right)\end{array}$ & $\begin{array}{l}\text { No. of } \\
\text { cholera cases }\end{array}$ & $\begin{array}{l}\text { Cholera incidence } \\
\text { (per million) }\end{array}$ & $\begin{array}{l}\text { Percentage of } \\
\text { cholera cases }(\%)\end{array}$ & $\begin{array}{l}\text { Percentage } \\
\text { of area }(\%)\end{array}$ \\
\hline$<5$ & 0 & $0 \cdot 00$ & $0 \cdot 00$ & $27 \cdot 67$ \\
$5-10$ & 41 & $0 \cdot 08$ & $1 \cdot 12$ & $33 \cdot 06$ \\
$10-15$ & 468 & $0 \cdot 30$ & $12 \cdot 77$ & $17 \cdot 35$ \\
$15-20$ & 1727 & $0 \cdot 65$ & $47 \cdot 13$ & $17 \cdot 76$ \\
$>20$ & 1428 & $1 \cdot 93$ & $38 \cdot 97$ & $39 \cdot 48$ \\
\hline
\end{tabular}

seafood contaminated by $V$. cholerae. The overlapped map of distance to coastline and cholera cases is shown in Figure $2 e$. The number and percentage of cholera cases for different levels of distance to coastline are given in Table 5. Most of the cholera cases are distributed in regions which are within $500 \mathrm{~km}$ of the coastline. However, there are few cholera cases in regions which are $>1500 \mathrm{~km}$ from the coastline. 
Table 2. Statistical analysis of precipitation and cholera in China between 2001 and 2008

\begin{tabular}{lllll}
\hline \hline $\begin{array}{l}\text { Average } \\
\text { precipitation }(\mathrm{mm})\end{array}$ & $\begin{array}{l}\text { No. of } \\
\text { cholera cases }\end{array}$ & $\begin{array}{l}\text { Cholera incidence } \\
\text { (per million) }\end{array}$ & $\begin{array}{l}\text { Percentage of } \\
\text { cholera cases }(\%)\end{array}$ & $\begin{array}{l}\text { Percentage } \\
\text { of area }(\%)\end{array}$ \\
\hline$<200$ & 18 & $0 \cdot 22$ & $0 \cdot 49$ & $25 \cdot 61$ \\
$200-400$ & 0 & $0 \cdot 00$ & $0 \cdot 00$ & $22 \cdot 19$ \\
$400-800$ & 201 & $0 \cdot 12$ & $5 \cdot 44$ & $27 \cdot 34$ \\
$>800$ & 3476 & $0 \cdot 92$ & $94 \cdot 07$ & $24 \cdot 86$ \\
\hline \hline
\end{tabular}

Table 3. Statistical analysis of elevation and cholera in China between 2001 and 2008

\begin{tabular}{lllll}
\hline \hline Elevation $(\mathrm{m})$ & $\begin{array}{l}\text { No. of } \\
\text { cholera cases }\end{array}$ & $\begin{array}{l}\text { Cholera incidence } \\
\text { (per million) }\end{array}$ & $\begin{array}{l}\text { Percentage of } \\
\text { cholera cases }(\%)\end{array}$ & $\begin{array}{l}\text { Percentage } \\
\text { of area (\%) }\end{array}$ \\
\hline$<500$ & 3194 & $85 \cdot 86$ & $0 \cdot 71$ & $0 \cdot 329$ \\
$500-1000$ & 182 & $4 \cdot 89$ & $0 \cdot 37$ & $0 \cdot 126$ \\
$1000-1500$ & 88 & $2 \cdot 37$ & $0 \cdot 27$ & $0 \cdot 179$ \\
$1500-2000$ & 21 & $0 \cdot 56$ & $0 \cdot 10$ & $0 \cdot 049$ \\
$2000-2500$ & 51 & $1 \cdot 37$ & $0 \cdot 65$ & $0 \cdot 065$ \\
$2500-3000$ & 184 & $4 \cdot 95$ & $6 \cdot 07$ & $0 \cdot 031$ \\
$>3000$ & 0 & $0 \cdot 00$ & $0 \cdot 00$ & $0 \cdot 222$ \\
\hline \hline
\end{tabular}

Table 4. Statistical analysis of river density and cholera in China between 2001 and 2008

\begin{tabular}{lllll}
\hline \hline $\begin{array}{l}\text { River density } \\
(\text { per } \mathrm{km})\end{array}$ & $\begin{array}{l}\text { No. of } \\
\text { cholera cases }\end{array}$ & $\begin{array}{l}\text { Cholera incidence } \\
\text { (per million) }\end{array}$ & $\begin{array}{l}\text { Percentage of } \\
\text { cholera cases }(\%)\end{array}$ & $\begin{array}{l}\text { Percentage } \\
\text { of area }(\%)\end{array}$ \\
\hline$<0 \cdot 02$ & 496 & $1 \cdot 00$ & $13 \cdot 51$ & $32 \cdot 35$ \\
$0 \cdot 02-0 \cdot 04$ & 1329 & $1 \cdot 00$ & $36 \cdot 19$ & $36 \cdot 27$ \\
$0 \cdot 04-0 \cdot 06$ & 861 & $0 \cdot 53$ & $23 \cdot 45$ & $22 \cdot 55$ \\
$0 \cdot 06-0 \cdot 08$ & 268 & $0 \cdot 29$ & $7 \cdot 30$ & $5 \cdot 88$ \\
$0 \cdot 08-0 \cdot 1$ & 302 & $0 \cdot 46$ & $8 \cdot 22$ & $1 \cdot 96$ \\
$>0 \cdot 1$ & 416 & $0 \cdot 75$ & $11 \cdot 33$ & $0 \cdot 98$ \\
\hline \hline
\end{tabular}

Table 5. Statistical analysis of distance to the sea and cholera in China between 2001 and 2008

\begin{tabular}{lllll}
\hline \hline $\begin{array}{l}\text { Distance to } \\
\text { coastline }(\mathrm{km})\end{array}$ & $\begin{array}{l}\text { No. of } \\
\text { cholera cases }\end{array}$ & $\begin{array}{l}\text { Cholera incidence } \\
\text { (per million) }\end{array}$ & $\begin{array}{l}\text { Percentage of } \\
\text { cholera cases (\%) }\end{array}$ & $\begin{array}{l}\text { Percentage of } \\
\text { area (\%) }\end{array}$ \\
\hline$<500$ & 2736 & $0 \cdot 35$ & $77 \cdot 35$ & $23 \cdot 43$ \\
$500-1000$ & 595 & $0 \cdot 38$ & $16 \cdot 82$ & $24 \cdot 34$ \\
$1000-1500$ & 188 & $0 \cdot 24$ & $5 \cdot 32$ & $13 \cdot 41$ \\
$1500-2000$ & 2 & $0 \cdot 04$ & $0 \cdot 06$ & $8 \cdot 73$ \\
$2000-2500$ & 0 & 0 & $0 \cdot 00$ & $10 \cdot 14$ \\
$2500-3000$ & 5 & $0 \cdot 13$ & $0 \cdot 14$ & $10 \cdot 49$ \\
$3000-3500$ & 9 & $0 \cdot 13$ & $0 \cdot 25$ & $8 \cdot 23$ \\
$>3500$ & 2 & $0 \cdot 07$ & $0 \cdot 06$ & $1 \cdot 22$ \\
\hline \hline
\end{tabular}

\section{Environmental factors and prediction model of cholera in Zhejiang province}

There were 752 cholera cases in Zhejiang province from 2001 to 2008. Figure $3 a$ shows the distribution of cases by month. There were cholera outbreaks in every year of the study period. The years of 2001 and 2005 had a relatively higher cholera magnitude than other years. The data exhibit a clear seasonality 


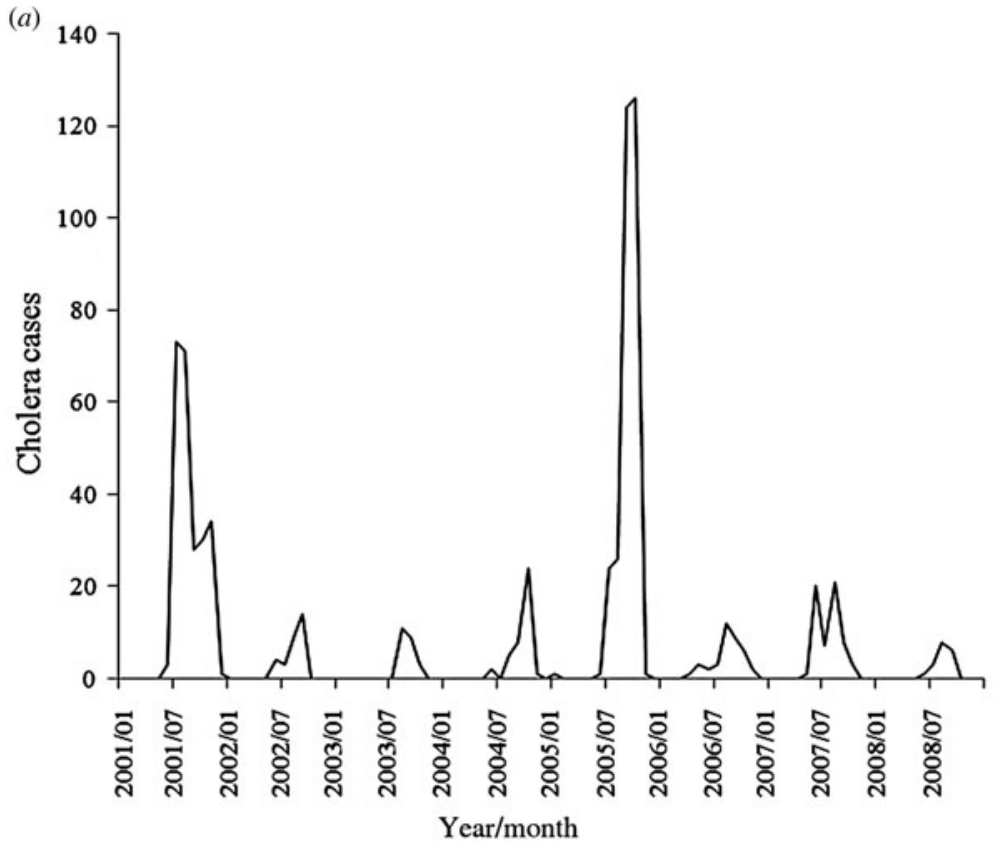

(b)
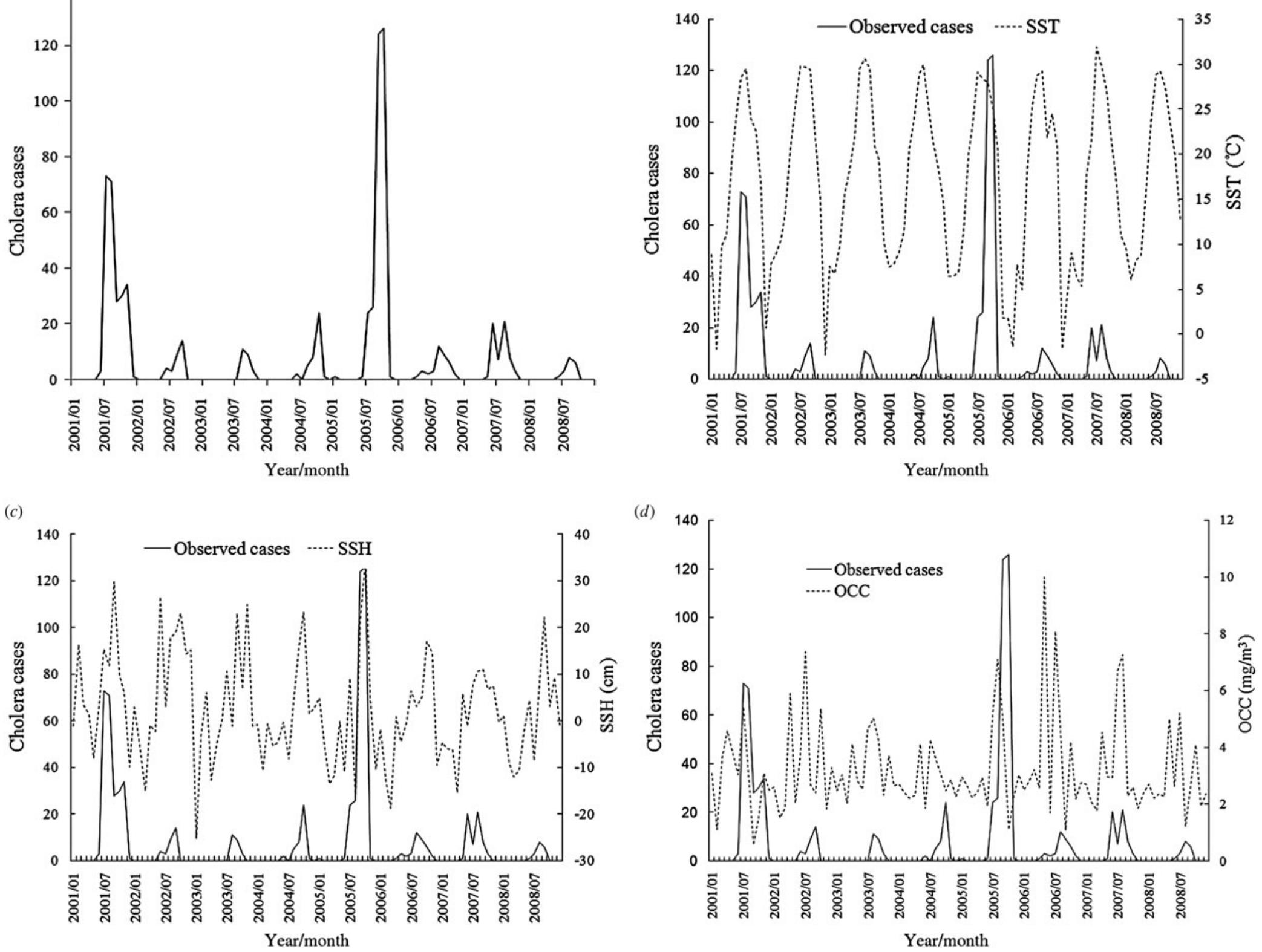

Fig. 3. Time plots of $(a)$ monthly cholera cases, $(b)$ monthly cholera cases and sea surface temperature (SST), $(c)$ monthly cholera cases and sea surface height (SSH), (d) monthly cholera cases and ocean chlorophyll concentration (OCC) in Zhejiang province, China during 2001-2008. 
Table 6. Descriptive statistics of oceanic environmental factors

\begin{tabular}{llccrr}
\hline \hline Environmental factors & No. of samples & Lowest value & Highest value & Average value & S.D. \\
\hline SST $\left({ }^{\circ} \mathrm{C}\right)$ & 96 & $-2 \cdot 31$ & $31 \cdot 87$ & $17 \cdot 09$ & $9 \cdot 47$ \\
SSH $(\mathrm{cm})$ & 96 & $-25 \cdot 16$ & $34 \cdot 79$ & $2 \cdot 51$ & $11 \cdot 59$ \\
OCC $\left(\mathrm{mg} / \mathrm{m}^{3}\right)$ & 96 & 0.56 & $9 \cdot 99$ & $3 \cdot 21$ & 1.62 \\
\hline \hline
\end{tabular}

SST, Sea surface temperature; SSH, sea surface height; OCC, ocean chlorophyll concentration.

Table 7. Summary of the model obtained for the study area

\begin{tabular}{|c|c|c|c|c|}
\hline $\begin{array}{l}\text { Model } \\
\text { predictors }\end{array}$ & Coefficient & S.E. & Sig. & $\begin{array}{l}95 \% \text { confidence } \\
\text { interval }\end{array}$ \\
\hline (Constant) & $-2 \cdot 604$ & $0 \cdot 403$ & $0 \cdot 000$ & $-3 \cdot 394$ to $-1 \cdot 814$ \\
\hline $\log \left(\mathrm{cho}_{\mathrm{t}-1}\right)$ & $1 \cdot 505$ & 0.092 & $0 \cdot 000$ & 1.326 to 1.686 \\
\hline Pre $_{t}$ & $-0 \cdot 107$ & 0.063 & $0 \cdot 090$ & -0.230 to 0.016 \\
\hline Pre $_{t-1}$ & $-0 \cdot 041$ & 0.085 & 0.630 & $-0 \cdot 208$ to $0 \cdot 126$ \\
\hline $\mathrm{Tem}_{t}$ & $-0 \cdot 229$ & $0 \cdot 034$ & $0 \cdot 000$ & $-0 \cdot 296$ to $-0 \cdot 162$ \\
\hline Tem $_{t-1}$ & $0 \cdot 346$ & $0 \cdot 045$ & $0 \cdot 000$ & $0 \cdot 257$ to 0.435 \\
\hline $\mathrm{SSH}_{t}$ & 0.073 & $0 \cdot 006$ & $0 \cdot 000$ & 0.062 to 0.085 \\
\hline$S S H_{t-1}$ & 0.027 & $0 \cdot 005$ & $0 \cdot 000$ & $0 \cdot 018$ to 0.037 \\
\hline$S S T_{t}$ & $0 \cdot 130$ & $0 \cdot 032$ & $0 \cdot 000$ & $0 \cdot 068$ to $0 \cdot 192$ \\
\hline$S S T_{t-1}$ & $-0 \cdot 178$ & 0.025 & $0 \cdot 000$ & $-0 \cdot 226$ to $-0 \cdot 129$ \\
\hline$O C C_{t}$ & $0 \cdot 114$ & 0.031 & $0 \cdot 000$ & 0.053 to 0.176 \\
\hline$O C C_{t-1}$ & $0 \cdot 096$ & $0 \cdot 029$ & $0 \cdot 001$ & $0 \cdot 040$ to $0 \cdot 152$ \\
\hline
\end{tabular}

with outbreaks concentrated in May-October, which are the warmer months in the study area. No case was reported during the coldest winter months from December to March.

We obtained monthly SST, SSH and OCC data from the coastal sea of Hangzhou Bay and created statistics of their parameters, as shown in Table 6. The average monthly SST of satellite data area between 2001 and 2008 was $17 \cdot 1{ }^{\circ} \mathrm{C}$, while the highest was $31 \cdot 9$ ${ }^{\circ} \mathrm{C}$ and the lowest $-2 \cdot 3{ }^{\circ} \mathrm{C}$. The SST of different months can vary greatly. The average SLA was $2.51 \mathrm{~cm}$. The height difference between the highest sea level and lowest sea level values can reach $60 \mathrm{~cm}$. The average monthly OCC of satellite data area between 2001 and 2008 was $3.21 \mathrm{mg} / \mathrm{m}^{3}$, while the lowest was $0.6 \mathrm{mg} / \mathrm{m}^{3}$ and the highest was $10 \mathrm{mg} / \mathrm{m}^{3}$.

Figure $3 b$ shows the monthly trend graphs of SST with cholera, which exhibit the obvious seasonality of SST and increase in cholera cases accompanied by SST in most years during 2001-2008. This is probably because warmer temperatures are much more suitable for the increased growth rate of vibrios. Where cholera cases reach their peak each year accords with the SST peak of about $30^{\circ} \mathrm{C}$, which is close to the optimal temperature for $V$. cholerae multiplication [29]. The time plot of SSH in Figure $3 c$ also exhibits a strong association with the number of cholera cases. The years of 2001 and 2005 which have the top-2 SSH peaks are exactly the years which have the top-2 number of cholera cases. The reason is that the higher SSH provides more vibrio-human contact from the extent of tidal intrusion of plankton into inland waters. The time plot in Figure $3 d$ shows an apparent pattern between OCC and the number of cholera cases, and it appears to have a delayed effect in some years.

To build the cholera prediction model it is necessary to first confirm the variables. According to previous analysis, we found that cholera has a significant relationship with temperature, precipitation, elevation, distance to coastline, SST, SSH and OCC. However, the geographical factors including elevation and distance to coastline are constants which are not suitable for inclusion in a temporal prediction model. Therefore, we only included the variables of temperature, precipitation, SST, SSH and OCC in the cholera prediction model in the coastal area of Zhejiang. Env $v_{t-i}$ in equation (1) can be expressed by the observed value of temperature, precipitation, SST, SSH and OCC in months $t$ and $t-1$. The prediction model for the study area can be expressed as

$$
\begin{aligned}
\log \left(\text { Chol }_{t}\right)= & a_{0}+a_{1} * S S T_{t}+a_{2} * S S T_{t-1} \\
& +a_{3} * S S H_{t}+a_{4} * S S H_{t-1}+a_{5} * \text { OCC }_{t} \\
& +a_{6} * \text { OCC }_{t-1}+a_{7} * \text { Pre }_{t}+a_{8} * \text { Pre }_{t-1} \\
& +a_{9} * \text { Tem }_{t}+a_{10} * \text { Tem }_{t-1} \\
& +a_{11} * \log \left(\text { Chol }_{t-1}+1\right),
\end{aligned}
$$

where $S S T_{t}, S S T_{t-1}, S S H_{t}, S S H_{t-1}, O C C_{t}, O C C_{t-1}$, Pre $_{t}$, Pre $_{t-1}$, Tem $_{t}$ and $\mathrm{Tem}_{t-1}$, represent the observed values of SST, SSH, OCC, precipitation and temperature in the months $t$ and $t-1$.

The final model parameters are shown in Table 7. Hypotheses of environmental factors driving cholera dynamics was tested by using a $5 \%$ rejection range 
for significant variables, the independent variable excluded from the final model is only Pre $_{t-1}$. The number of cholera cases in the previous month has the largest effect on the new increased cholera magnitude; the environmental factors of concurrent temperature, precipitation, SSH, SST and OCC, which affect the reproduction and transmission of $V$. cholerae are also important predictors for cholera magnitude in the study area.

\section{CONCLUSION}

This study has analysed the environmental factors of the spatial distribution of cholera in China. It shows elevation has a significant impact on the distribution of cholera. Low-elevation areas tend to have more cholera cases. More than $80 \%$ of cholera cases were distributed in areas with elevation of $<500 \mathrm{~m}$, while no cases were distributed in areas of $>3000 \mathrm{~m}$ elevation. Climatic factors have a strong impact on cholera distribution in China. Cholera incidence rises as precipitation increases, and $>90 \%$ of cases are located in the humid areas with an annual precipitation of $>800 \mathrm{~mm}$. The areas with higher temperatures have higher incidence of cholera.

The study also built a prediction model in a coastal area of China. Quantitative analysis revealed the effects of aquatic environments near Hangzhou Bay on cholera incidence in Zhejiang province. Our study which was based on 8-year monthly material in temporal dimension has validated the previous literature that temperature, precipitation and indirect measurements of SST, SSH and OCC have significant association with local cholera outbreaks or magnitude $[4,13,20,30]$. Our results show that SST is a very important indicator for cholera magnitude during oceanic environmental factors. SST has a strong effect not only on the concurrent cholera magnitude but also on the magnitude with a 1-month lag, and so is the variable of SSH. OCC has a 1-lag effect on number of cholera cases. We built a prediction model for cholera in Zhejiang province according to the Macro environment-SIR model based on these environmental factors. Synthetically using RS, meteorological data and historical cholera data we built the prediction model which considered the secondary transmission of cholera. It indicates that RS and GIS have great potential for designing an early warning system for cholera. Combined factors of oceanic environmental and geographical factors will enhance the prediction of cholera.

\section{ACKNOWLEDGEMENTS}

This work was supported by the Youth Foundation of Director of Institute of Remote Sensing and Digital Earth of Chinese Academy of Sciences (Y3SJ8600CX), the National High Technology Research and Development Program of China (2013AA12A302), the Young Talents program funding of State Key Laboratory of Remote Sensing Science (13RC-08), the Major Program on Science of State Key Laboratory of Remote Sensing Science (ZD12-5) and the National Natural Science Foundation of China (41 301 502).

\section{DECLARATION OF INTEREST}

None.

\section{REFERENCES}

1. Antarpreet $\mathbf{J}$, et al. A water marker monitored by satellites to predict seasonal endemic cholera. Remote Sensing Letters 2013; 4: 822-831.

2. Ali M, et al. Identifying environmental risk factors for endemic cholera: a raster GIS approach. Health \& Place 2002; 8: 201-210.

3. Bouma M, Pascual M. Seasonal and interannual cycles of endemic cholera in Bengal 1891-1940 in relation to climate and geography. Hydrobiologia 2001; 460: 147-156.

4. Emch M, et al. Local population and regional environmental drivers of cholera in Bangladesh. Environment Health 2010; 9: 2.

5. Koelle K, et al. Refractory periods and climate forcing in cholera dynamics. Nature 2005; 436: 696-700.

6. Pascual M, et al. Cholera dynamics and El Ninosouthern oscillation. Science 2000; 289: 1766.

7. Kanungo S, et al. Cholera in India: an analysis of reports, 1997-2006. Bulletin of the World Health Organization 2010; 88: 185-191.

8. Borroto R, Martinez-Piedra R. Geographical patterns of cholera in Mexico, 1991-1996. International Journal of Epidemiology 2000; 29: 764-772.

9. Gil AI, et al. Occurrence and distribution of Vibrio cholerae in the coastal environment of Peru. Environmental Microbiology 2004; 6: 699-706.

10. Bompangue D, et al. Cholera epidemics, war and disasters around Goma and Lake Kivu: an eight-year survey. PLOS Neglected Tropical Diseases 2009; D3: e436.

11. Fernández $\mathbf{L}$, et al. Influence of temperature and rainfall on the evolution of cholera epidemics in Lusaka, Zambia, 2003-2006: analysis of a time series. Transactions of the Royal Society of Tropical Medicine and Hygiene 2009; 103: 137-143.

12. Fleming G, Van Der Merwe M, McFerren G. Fuzzy expert systems and GIS for cholera health risk prediction 
in southern Africa. Environmental Modelling Software 2007; 22: 442-448.

13. Mendelsohn J, Dawson T. Climate and cholera in KwaZulu-Natal, South Africa: the role of environmental factors and implications for epidemic preparedness. International Journal of Hygiene and Environmental Health 2008; 211: 156-162.

14. Mintz ED, Guerrant RL. Global health: a lion in our village - the unconscionable tragedy of cholera in Africa. New England Journal of Medicine 2009; 36: 1060-1063.

15. Paz S. Impact of temperature variability on cholera incidence in Southeastern Africa, 1971-2006. EcoHealth 2009; 6: 340-345.

16. Xu M, et al. District prediction of cholera risk in China based on environmental factors. Chinese Science Bulletin 2013; 58: 2798-2804.

17. Constantin de Magny G, et al. Environmental signatures associated with cholera epidemics. Proceedings of the National Academy of Sciences 2008; 105: 17676-17681.

18. Cash BA, et al. Disentangling the impact of ENSO and Indian Ocean variability on the regional climate of Bangladesh: implications for cholera risk. Journal of Climate 2010; 23: 2817-2831.

19. Emch M et al. Local environmental predictors of cholera in Bangladesh and Vietnam. American Journal of Tropical Medicine and Hygiene 2008; 78: 823-854.

20. Lobitz B, et al. Climate and infectious disease: use of remote sensing for detection of Vibrio cholerae by indirect measurement. Proceedings of the National Academy of Sciences USA 2000; 97: 1438-1443.

21. Chang CY, et al. The novel H1N1 Influenza A global airline transmission and early warning without travel containments. Chinese Science Bulletin 2010; 55: 3030 3036.

22. Cao CX, et al. Risk analysis for the highly pathogenic avian influenza in mainland china using meta-modeling. Chinese Science Bulletin 2010; 55: 4168-4178.

23. Ali M, et al. The spatial epidemiology of cholera in an endemic area of Bangladesh. Social Science \& Medicine 2002; 55: 1015-1024.

24. Carrel M, et al. Spatio-temporal clustering of cholera: The impact of flood control in Matlab, Bangladesh, 1983-2003. Health \& Place 2009; 15: 771-782.

25. Kistemann T, Dangendorf F, Schweikart J. New perspectives on the use of Geographical Information Systems (GIS) in environmental health sciences. International Journal of Hygiene and Environmental Health 2002; 205: 169-181.

26. Sasaki S, Suzuki H, Igarashi K. Spatial analysis of risk factor of cholera outbreak for 2003-2004 in a periurban area of Lusaka, Zambia. American Journal of Tropical Medicine and Hygiene 2008; 79: 414 435.

27. Akanda A, Jutla A, Islam S. Dual peak cholera transmission in Bengal Delta: a hydroclimatological explanation. Geophysical Research Letters 2009, 36: L19401-L19407.

28. Singleton F, et al. Effects of temperature and salinity on Vibrio cholerae growth. Applied and Environmental Microbiology 1982; 44: 1047-1058.

29. Singleton F, Attwell R, Jangi S. Effects of temperature and salinity on Vibrio cholerae growth. Applied and Environmental Microbiology 1982; 44: 1047-1058.

30. Emch M, et al. Local environmental predictors of cholera in Bangladesh and Vietnam. American Journal of Tropical Medicine and Hygiene 2008; 78: 823-854. 